\title{
Multiple choroidal osteomas in a boy - a rare presentation: a case report
}

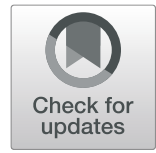

\author{
Arup Deuri, Deepanjan Ghosh, Jayant Ekka (D) and Vijaya Agarwalla
}

\begin{abstract}
Background: Choroidal osteoma is rare clinical entity of unknown etiology, characterized by formation of mature cancellous bone within the choroid. It typically affects young females, with no racial predilection. Vision loss occurs mainly due to photoreceptor degeneration secondary to decalcification and/or development of choroidal neovascularization especially if located at the subfoveal area.

Case presentation: Our case is 9-year-old Indian (Indo-Aryan) boy identified incidentally with clinical features suggestive of choroidal osteoma with marked diminution of vision. Spectral domain optical coherence tomography demonstrated high reflectivity from the choroid and atrophy of the overlying retinal layers and B-scan ultrasound demonstrated multiple highly reflective calcified lesions within the choroid.

Conclusion: Although available literature shows that the occurrence of this rare clinical entity is more commonly seen in young females, our case report has shown that it may be seen at a very early age. The treatment options are still not available if significant atrophy of retinal pigment epithelium has already occurred; however, vision loss due to associated choroidal neovascularization may be treated with currently available treatment options. In our case, the vision loss was due to the significant atrophy of the retinal layers. Choroidal neovascularization was not seen and our patient was advised to attend follow-up regularly.
\end{abstract}

Keywords: Choroid, Osteoma, RPE, Decalcification

\section{Background}

Choroidal osteoma is a benign ossifying disorder with formation of mature cancellous bone in the choroid. The exact etiology is still unknown. The first case was presented at a meeting of the Verhoeff Society in 1975 and the case was published by Gass et al. in 1978 [1]. The incidence of the disease is extremely rare. No data on the prevalence are available in the literature. To date, only a few cases have been reported. The largest case series included 74 eyes of 61 patients with choroidal osteoma followed up over a period of 26 years [2]. There is no racial predilection; however, most reports were of white patients [3]. It typically affects young adults; there is a female predilection. It appears as orange-yellow to yellow-white lesions with a distinct margin with blood vessels overlying them. The lesion color depends on the level of overlying retinal pigment epithelium (RPE) depigmentation [1]. In the early stages, they tend to be

\footnotetext{
* Correspondence: ekkajayant@gmail.com

Department of Ophthalmology, Assam Medical College, Dibrugarh, Assam, India
}

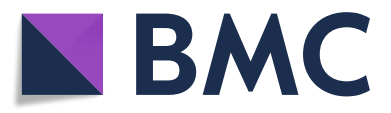

(c) The Author(s). 2019 Open Access This article is distributed under the terms of the Creative Commons Attribution 4.0 International License (http://creativecommons.org/licenses/by/4.0/), which permits unrestricted use, distribution, and

reproduction in any medium, provided you give appropriate credit to the original author(s) and the source, provide a link to the Creative Commons license, and indicate if changes were made. The Creative Commons Public Domain Dedication waiver (http://creativecommons.org/publicdomain/zero/1.0/) applies to the data made available in this article, unless otherwise stated.

\section{Case presentation}

A 9-year-old Indian (Indo-Aryan) boy diagnosed as having pan-sinusitis was referred to us from an Ear, Nose, and Throat (ENT) department with complaints of swelling over the left side of his face involving left lower lid to rule out any ocular manifestation. He gave a history of swelling over the left side of his face of approximately 10 days' duration. It was insidious in onset, gradually progressive in nature, and involved the left lower lid; it was not associated with pain and fever. There was no associated systemic disease. On examination, the best corrected visual acuity (BCVA) for his left eye was hand movement and for his right eye it was $6 / 6$. He was unaware of diminished vision in his left eye. On dilated 


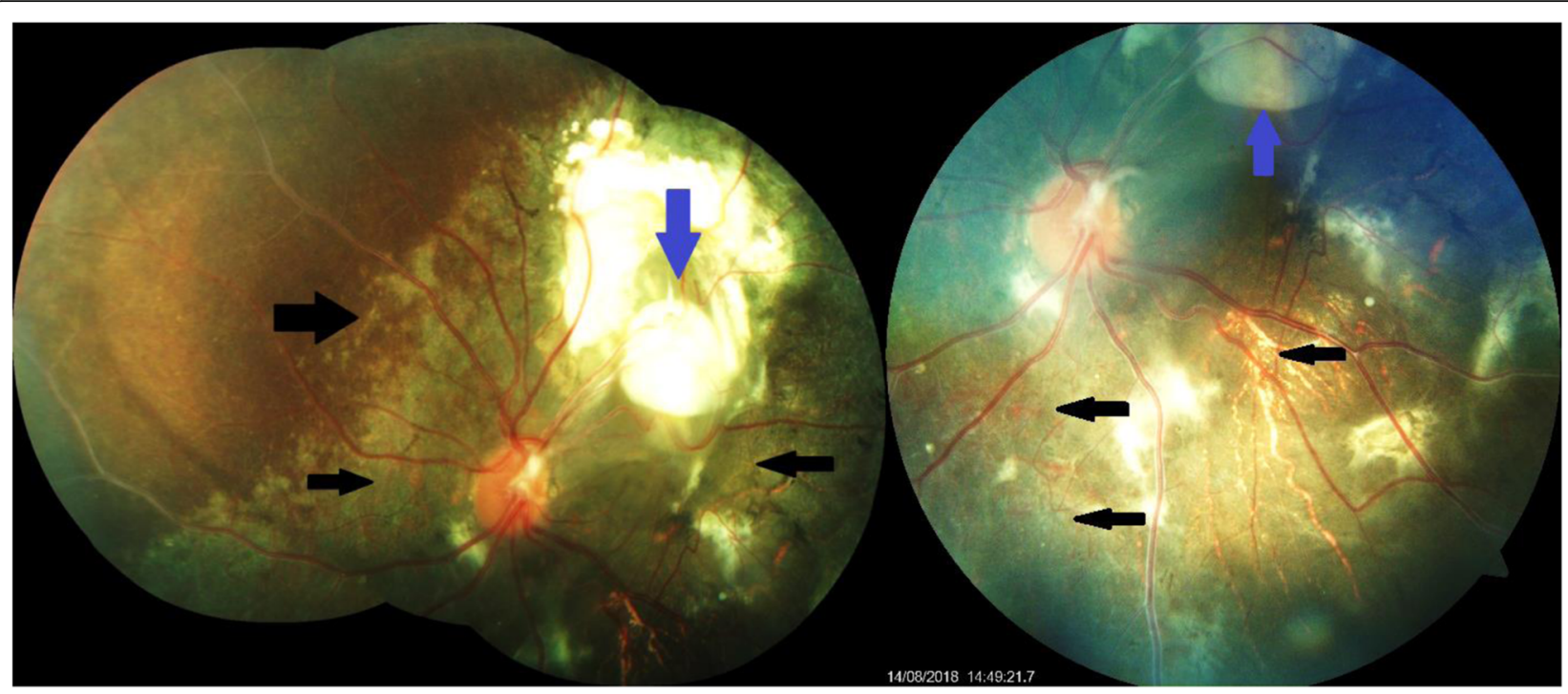

Fig. 1 Fundus photograph of the left eye showing multiple choroidal osteomas superotemporally (blue arrows) and areas of retinal pigment epithelium depigmentation (black arrows)

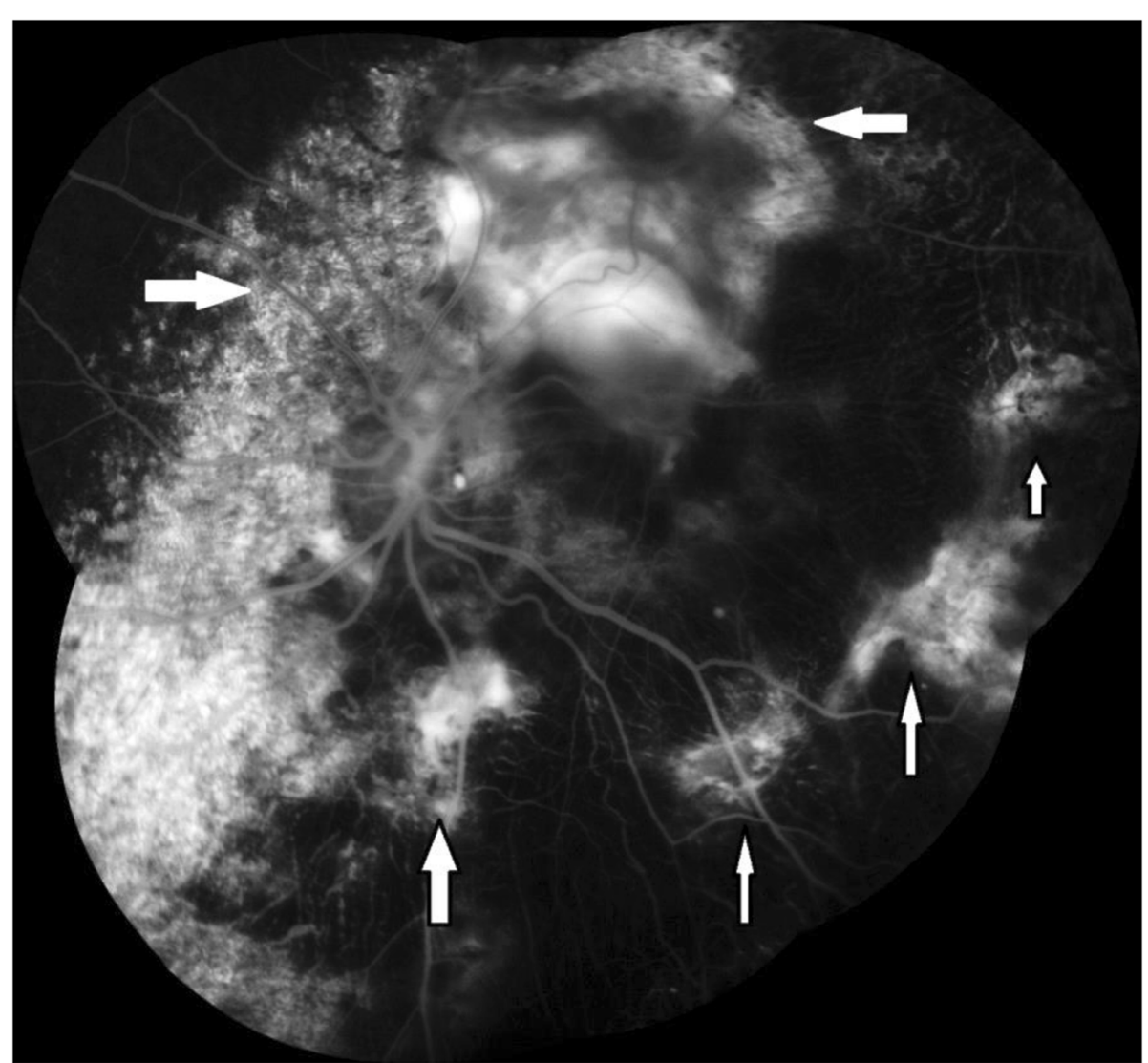

Fig. 2 Fundus fluorescein angiography of left eye showing areas of patchy hyperfluorescence corresponding to the areas of retinal pigment epithelium depigmentation (white arrows) 
fundus examination we observed two yellowish white lesions with well-demarcated borders located superotemporally indicative of active lesions, which were associated with nearby areas of RPE depigmentation and pigment clumps extending into the macular area, which were suggestive of degeneration of overlying retinal layers indicative of decalcified lesions in his left eye (Fig. 1). Fundus of his right eye was normal.

Fundus fluorescein angiography (FFA) revealed areas of early granular hyperfluorescence corresponding to the areas of RPE depigmentation and late hyperfluorescence over the calcified lesion with some interspersed areas of hypofluorescence corresponding to the areas of pigment clumps in the left eye (Fig. 2).

Spectral domain optical coherence tomography (SDOCT) was performed and revealed high reflectivity from the choroid with marked thinning of overlying retinal layers including photoreceptor inner/outer segment junction (Fig. 3).

B-scan ultrasound (USG) of his left eye demonstrated a large irregular echogenic calcified lesion of $7.1 \times 3.9 \mathrm{~mm}$ in the posterior choroid near to the optic disc region and extending up to optic disc, and another smaller echogenic calcified foci in the posterolateral choroid both nasally and temporally. The nasal lesion was $1.3 \mathrm{~mm}$ and temporal lesion was 1.5 mm (Fig. 4).

Examination of his right eye was normal. All routine blood investigations were normal including serum calcium and parathyroid hormone level. As there was already a setup of decalcification with loss of RPE/ photoreceptor and marked diminished vision, and the lesion extended into the foveal region, we asked our patient to attend follow-ups at monthly intervals to monitor the subsequent progression or regression of the

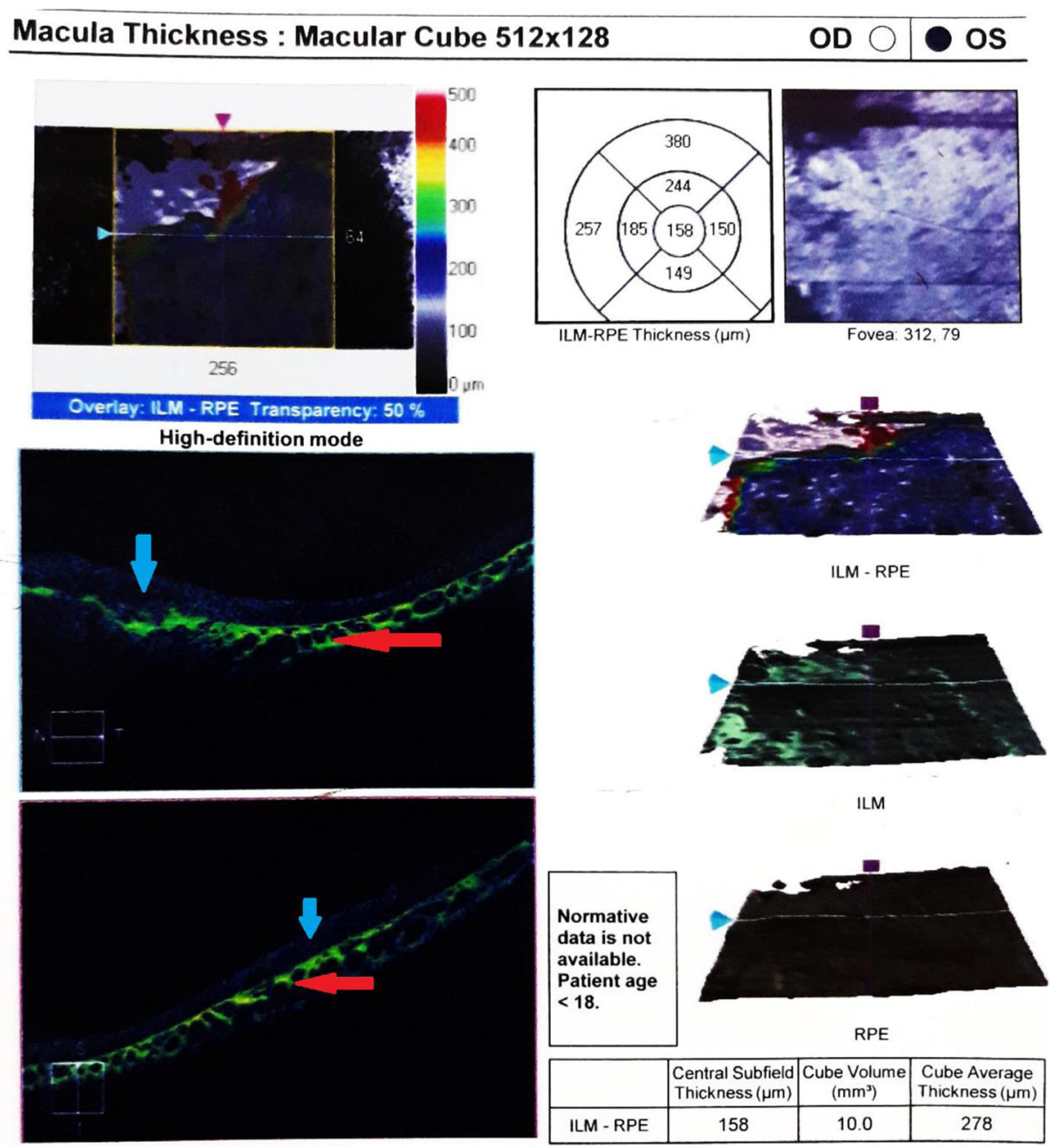

Fig. 3 Spectral domain optical coherence tomography of macula of left eye showing high reflectivity from the choroid (red arrows) and thinning of the retinal layers (blue arrows). ILM inner limiting membrane, RPE retinal pigment epithelium 


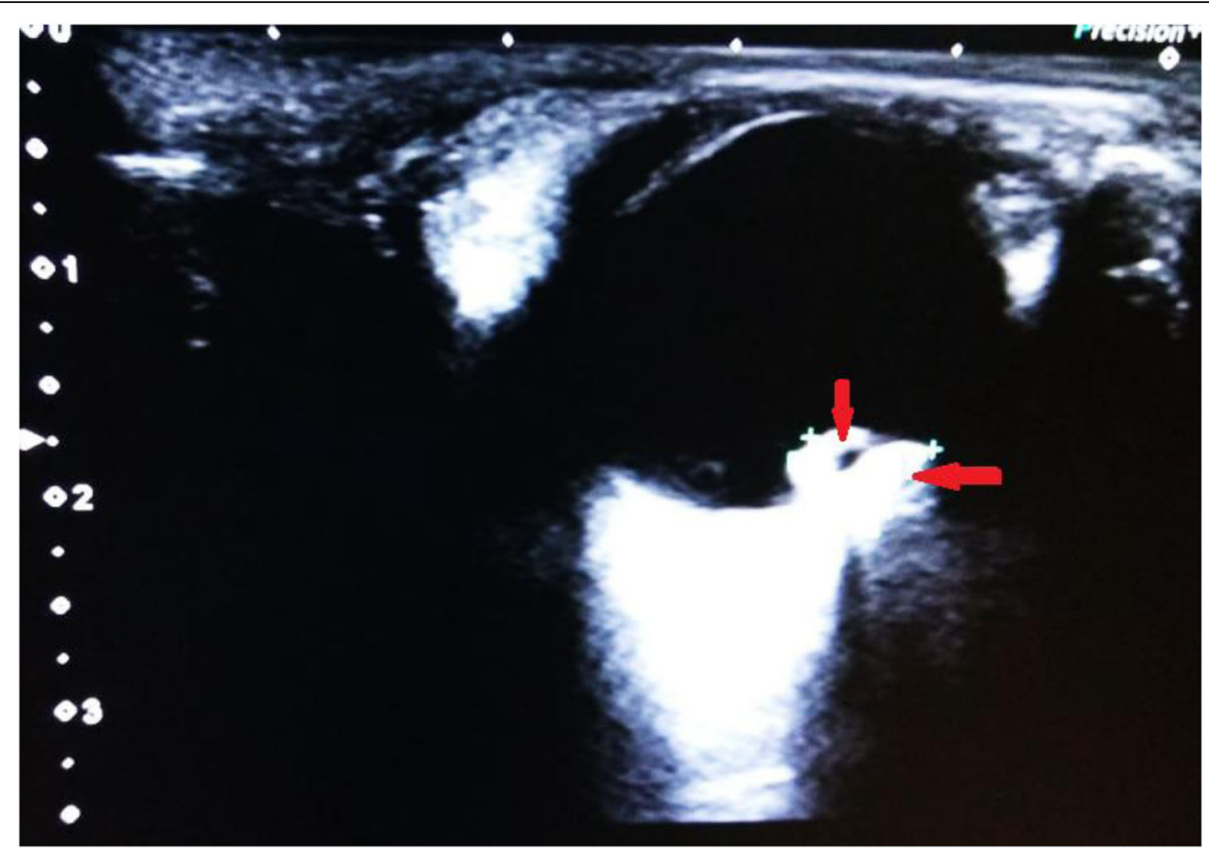

Fig. 4 B-scan ultrasound of left eye showing echogenic calcified lesion in the choroid (red arrows)

tumor, because of the non-availability of a reliable treatment option.

\section{Discussion}

Choroidal osteoma is a rare benign ossifying disorder of the choroid. In our case, our patient was a 9-year-old boy. In the largest case series on choroidal osteoma including 74 eyes of 61 patients followed up for a period of 26 years, Carol and colleagues demonstrated that choroidal osteoma is a disease of young females [2]. They found that choroidal osteoma showed evidence of growth in $51 \%$ of eyes and decalcification in nearly $50 \%$ of eyes by 10 years. In their series, decalcification of choroidal osteoma was usually associated with poor vision [2]. Decalcification was hence considered a significant risk factor for poor long-term visual acuity. Decalcification commonly occurs concurrently with overlying RPE alterations and atrophy of the choriocapillaries, both of which could lead to photoreceptor degeneration and poor visual acuity. Shields and colleagues found that the decalcified portion of osteoma displayed an overlying marked thinning to absent outer retina and photoreceptor layers (100\%), compared with the calcified portion with preserved intact outer retina (95\%) and intact photoreceptor layer (100\%) [5]. The optical coherence tomography (OCT) findings of our case also revealed the diffuse atrophy of the outer retina on the decalcified lesion involving the macular area and explained why our patient's vision was poor.

The etiology of choroidal osteoma is still unknown. It has been suggested that it is an osseous choristoma [8].
This suggestion is supported by peripapillary location, a site favored by other developmental tumors and by occurrence of the osteoma in the absence of any other disease process. An alternative cause is secondary ossification following inflammation or trauma to the orbit or periorbital tumor. A case of multiple osteomas developing in association with bilateral pseudotumors of the orbit raised the possibility that inflammation may have a part in the cause [9]. In our case, there was associated pan-sinusitis with multiple choroidal osteomas. Treatment options for foveal choroidal osteoma are limited. Photodynamic therapy (PDT) is a reasonable choice in the case of extrafoveal CNV lesions. Observation is the indicated management where there are no symptoms, with fundus examination at regular intervals monitoring for signs of CNV. Shields et al. also reported a case of extrafoveal CNV successfully treated with PDT [10]. However, the author inserted a proviso at the end of the case report that treatment of subfoveal CNV with PDT may result in worse visual acuity due to decalcification and associated RPE loss. More recently, antivascular endothelial growth factor (anti-VEGF) drugs have been used off license to treat $\mathrm{CNV}$ secondary to choroidal osteoma with good effect. In the future, more studies with long-term follow-up may help to define an appropriate time interval when intervention can be performed to prevent tumor growth or decalcification.

\section{Conclusion}

Choroidal osteoma is a rare benign disorder of unknown etiology; the literature showed a higher incidence in 
young females. However, it may occur at a very early age. Treatment options are still not available; also, early detection of the condition is incidental. Most of the time, a patient presents with symptoms of diminished vision when significant atrophy of retinal layers has already occurred. If diagnosed incidentally, the patient should be followed up regularly to detect the development of CNV or atrophy of retinal layers, so that loss of vision can be minimized. The strengths of this case report include its novelty; we describe a rare disease process involving the retina, with significant reduction in vision. The workup of our patient was quite thorough, as it involved multiple hospital admissions and subspecialty evaluations. The limitations of this case report include no follow-up data, as our patient did not turn up for follow-up. Curative treatment options are not yet available for this entity.

\section{Acknowledgements}

Not applicable.

\section{Authors' contributions}

Both $A D$ and DG examined the patient clinically, analyzed investigation data, and discussed the case with the relevant consulting physicians. JE and VA were the major contributors in drafting the manuscript. AD and DG provided a supervising and editorial role. Both $A D$ and $D G$ read and approved the

final manuscript. All authors read and approved the final manuscript.

\section{Funding}

Not applicable.

Availability of data and materials

Not applicable.

Ethics approval and consent to participate

Not applicable.

\section{Consent for publication}

Written informed consent was obtained from the patient's legal guardian(s) for publication of this case report and any accompanying images. A copy of the written consent is available for review by the Editor-in-Chief of this journal.

\section{Competing interests}

The authors declare that they have no competing interests.

Received: 23 January 2019 Accepted: 27 June 2019

Published online: 02 August 2019

\section{References}

1. Gass JD, Guerry RK, Jack RL, Harris G. Choroidal osteoma. Arch Ophthalmol. 1978;96:428-35.

2. Shields $\mathrm{CL}$, Sun $\mathrm{H}$, Demirci $H$, Shields JA. Factors predictive of tumor growth, tumor decalcification, choroidal neovascularization, and visual outcome in 74 eyes with choroidal osteoma. Arch Ophthalmol. 2005;123:1658-66.

3. Ryan SJ. Retina. Los Angeles, CA: Mosby; 2006 p. 819-28.

4. Chen J, Lee L, Gass JD. Choroidal osteoma: Evidence of progression and decalcification over 20 years. Clin Exp Optom. 2006;89:90-4.

5. Shields CL, Perez B, Materin MA, Mehta S, Shields JA. Optical coherence tomography of choroidal osteoma in 22 cases: Evidence for photoreceptor atrophy over the decalcified portion of the tumor. Ophthalmology. 2007; 114:e53-58.

6. Trimble SN, Schatz H. Decalcification of a choroidal osteoma. $\mathrm{Br} J$ Ophthalmol. 1991;75:61-3.

7. Trimble SN, Schatz H, Schneider, GB. Spontaneous decalcification of a choroidal osteoma. Ophthalmology. 1988;65:631-4.
8. Williams AT, Font RL, Van Dyk HL, Riekhof FT. Osseous choristoma of the choroid simulating choroidal melanoma: association with a positive 32P test. Arch Ophthalmol. 1978;96:1874-77.

9. Katz RS, Gass JM. Multiple choroidal osteomas developing in association with recurrent orbital inflammatory pseudotumor. Arch Ophthalmol. 1983; 101:1724-27.

10. Shields CL, Materin MA, Mehta S, Foxman BT, Shields JA. Regression of extrafoveal choroidal osteoma following phtodynamic therapy. Arch Ophthalmol. 2008;126:135-7.

\section{Publisher's Note}

Springer Nature remains neutral with regard to jurisdictional claims in published maps and institutional affiliations.
Ready to submit your research? Choose BMC and benefit from:

- fast, convenient online submission

- thorough peer review by experienced researchers in your field

- rapid publication on acceptance

- support for research data, including large and complex data types

- gold Open Access which fosters wider collaboration and increased citations

- maximum visibility for your research: over $100 \mathrm{M}$ website views per year

At BMC, research is always in progress.

Learn more biomedcentral.com/submissions 